\title{
Two new species of the genus Pholcus (Araneae: Pholcidae) from Taihang Mountains, China, with first report of the female of Pholcus oculosus
}

\author{
Yanqiu Peng \& Feng Zhang*
}

Peng, Y. \& Zhang, F. 2011: Two new species of the genus Pholcus (Araneae: Pholcidae) from Taihang Mountains, China, with first report of the female of Pholcus oculosus. — Entomol. Fennica 22: 78-84.

Two new species of the genus Pholcus from Taihang Mountains, China, are reported: Pholcus papilionis sp. n. and P. suboculosus sp. n. The female P. oculosus Zhang \& Zhang, 2000 is reported for the first time.

Y. Peng, College of Life Science, Hebei University, Baoding, 071002, China; Email: qiuzi2164@163.com

F. Zhang (*corresponding author), College of Life Science, Hebei University, Baoding,071002, China; E-mail: dudu06042001@163.com

Received 5 January 2011, accepted 4 May 2011

\section{Introduction}

Pholcus Walckenaer, 1805 is the largest genus of the family Pholcidae, with 174 species reported worldwide (Platnick 2011, Li \& Wang 2011). Zhang and Zhu (2009) revised the 55 Chinese Pholcus species. Tong \& Li (2010) and Tong \& Ji (2010) described another 11 Pholcus species from China.

Pholcus species are small to medium size, with conspicuously large and strong male pedipalps (Huber 1995). The genus can be distinguished from other pholcids by the projections of the male bulb (appendix, embolus and uncus) and the apophyses on male chelicerae. Externally, the female genitalia are usually relatively simple, but the internal morphology is complicated (Huber 1998).

Taihang Mountain $\left(34^{\circ} 34^{\prime}-40^{\circ} 43^{\prime} \mathrm{N}, 110^{\circ}\right.$ $\left.14^{\prime}-114^{\circ} 33^{\prime} \mathrm{E}\right)$ is located in the eastern edge of the Loess Plateau between Shanxi and Hebei provinces. The mountain range extends over $400 \mathrm{~km}$ from north to south and has an average elevation of 1,500 to 2,000 meters. The spider fauna of Pholcus is rich and abundant. Ten Pholcus species have been reported from Taihang Mountain (Zhu et al. 1983, 1986, Song et al. 1999, Zhang \& Zhang 2000, Zhang et al. 2005, Zhang \& Zhu 2009). In this study, we describe two new Pholcus species, Pholcus papilionis sp. n. and $P$. suboculosus sp. n., and describe the female of $P$. oculosus for the first time.

\section{Material and methods}

All measurements are given in millimeters. Carapace length was measured from the anterior margin to the rear margin, excluding the clypeus. Total length is the sum of carapace and abdomen length, regardless of the petiolus. The measurement of leg I is: total length (femur + patella + tibia + metatarsus + tarsus). All specimens were preserved in $75 \%$ alcohol, examined, illustrated and measured under a Nikon SMZ1500 stereomicroscope equipped with an Abbe draw- 


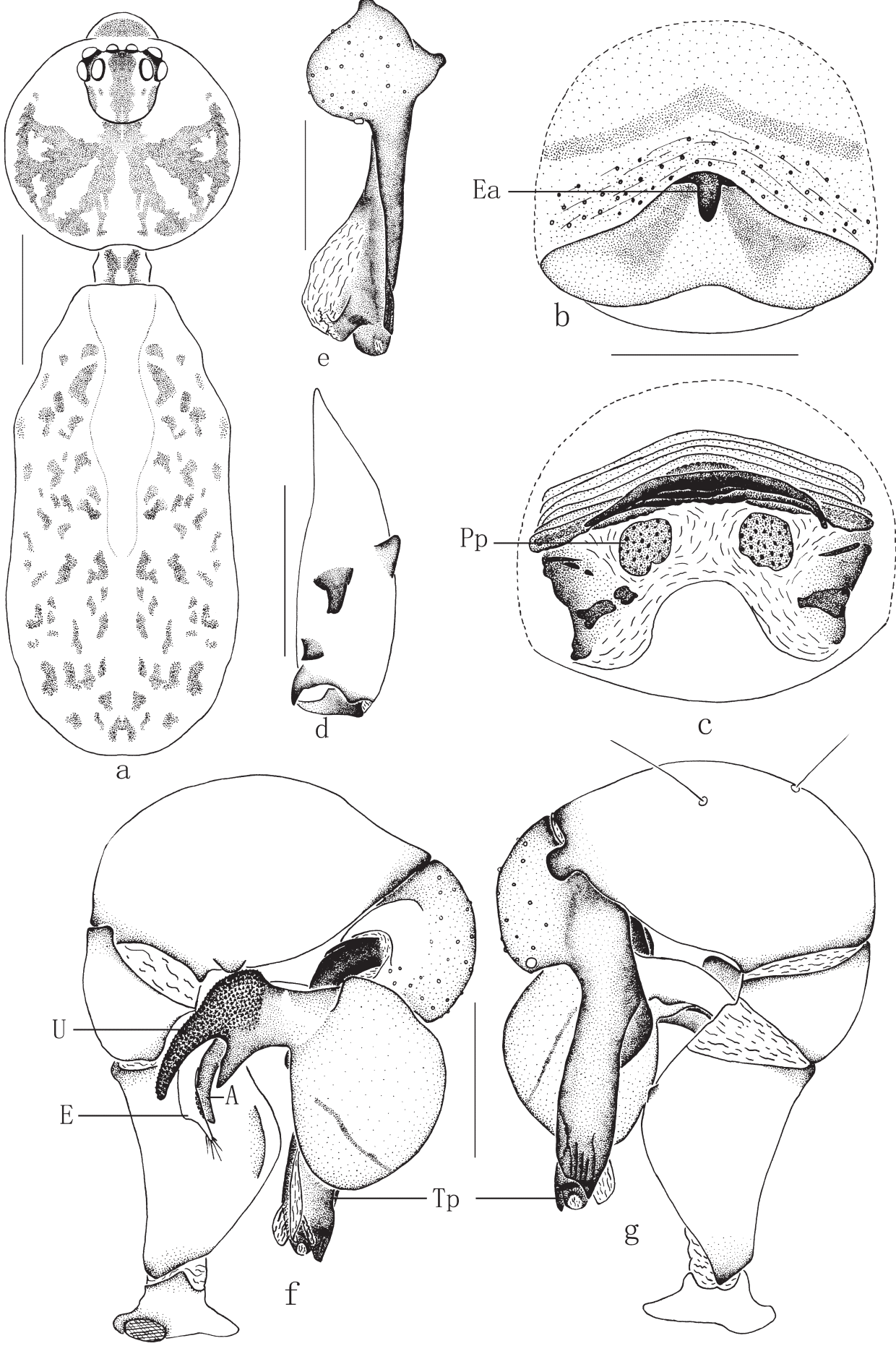

Fig. 1. Pholcus papilionis sp. $\mathbf{n}$. - a. Male body, dorsal view. - b. Epigynum, ventral view. - c.

Epigynum, dorsal view. $-d$. Male left chelicera, frontal view. - e. Left procursus, dorsal view. $-f$. Left palp, prolateral view. - g. Left palp, retrolateral view. Scale lines: a, $1.0 \mathrm{~mm}$; b-g, $0.5 \mathrm{~mm}$. Abbreviations: A, appendix; E, embolus; Ea, epigynal apophysis; Pp, pore plates; Tp, tip of the procursus; U, uncus. 
ing device. Specimens of the new species were deposited in the Museum of Hebei University (MHBU), Baoding, China.

Abbreviations used in the text: ALE $=$ anterior lateral eye; $\mathrm{AME}=$ anterior median eye; $\mathrm{AME}-\mathrm{AME}=$ distance between AMEs; PLE = posterior lateral eye; $\mathrm{PME}=$ posterior median eye; $\mathrm{A}=$ appendix; $\mathrm{E}=$ embolus; $\mathrm{Ea}=$ epigynal apophysis; $\mathrm{Pp}=$ pore plates; $\mathrm{Tp}=$ tip of the procursus; $\mathrm{U}=$ uncus.

\section{Taxonomy}

Pholcus Walckenaer, 1805

Pholcus Walckenaer 1805: 80. Simon 1893: 470-471. Huber 2000: 77. Huber 2001: 108-111. Hu 2001: 81, Zhang \& Zhu, 2009.

Type species: Aranea phalangioides Fuesslin, 1775.

\subsection{Pholcus papilionis sp. n. (Figs. 1a-g)}

Type material. Holotype: $\widehat{\jmath}$, China: Shanxi Province, Yu County $\left(38^{\circ} 01^{\prime} \mathrm{N}, 113^{\circ} 37^{\prime} \mathrm{E}\right)$, Mount Zhulong, 22.VII.2010, Sheng-Tao Guo leg. Paratypes: $2 \hat{\jmath}, 10$, , same data as holotype (MHBU).

Diagnosis. This new species is similar to $P$. phoenixus Zhang \& Zhu, 2009 and P. wangtian Tong \& Ji, 2010, but can be distinguished by the presence of appendix on palpal bulb, the distinctly long, thin, fork-shaped uncus, and the epigynum with brown butterfly-shaped marking.

Description. Male holotype. Total length 5.01: cephalothorax 1.51 long, 1.71 wide; abdomen 3.50 long, 1.64 wide. Leg I: 40.41 (10.10+ $0.71+10.61+16.37+2.62)$, tibia II: 7.33 , tibia III: 4.85, tibia IV: 6.65; tibia I L/D: 50.30. Prosoma shape as in Fig. 1a. Carapace yellowish, with brown stripes radiated from median; ocular area yellowish, with brown bands; clypeus dark ochre, with indistinct marks; sternum brown, without marks. AME-AME 0.05. Diameter AME 0.10 ALE 0.16, PME 0.16, PLE 0.17. Chelicerae with a pair of black apophyses distally, a pair of black apophyses frontally and a pair of unsclerotized rounded apophyses proximolaterally (Fig. 1d). Legs yellow, dark brown on patella and basal part of tibiae, whitish on distal femora and tibiae, with dark rings on femora and tibiae. Abdomen pale gray, with large spots dorsally and laterally. Palpal bulb with three projections: uncus with two narrow branches, and long one covered with small scales; appendix machete-shaped; embolus long, with simple brushshaped processes distally. Procursus tip relatively simple (Figs. 1e-g).

Variation. Tibia I in two other males: 8.63, 9.37. Body length in two other males: 3.90, 4.22.

Female. Similar to male. Total length $3.77-$ 4.26. One of the female paratypes is measured: body length 3.77: cephalothorax 1.42 long, 1.60 wide; abdomen 2.35 long, 1.21 wide. Tibia I: 7.03. AME-AME 0.04. Diameter AME 0.08, ALE 0.17, PME 0.16, PLE 0.16. Epigynum roughly triangular (Fig. 1b), with a short, knobshaped apophysis anteriorly and a brown butterfly-shaped marking medially. Dorsal view as in Fig. 1c, with wavy sclerotized arch anteriorly, and a pair of almost oval pore plates.

Etymology. The specific name is derived from Latin word "papilionis", meaning butterflyshaped and referring to the shape of the epigynal marking.

Distribution. China (Shanxi).

\subsection{Pholcus suboculosus sp. n. (Figs. 2a-g)}

Type material. Holotype: ${ }^{\lambda}$, China: Shanxi Province, Huguan County $\left(35^{\circ} 11^{\prime} \mathrm{N}, 113^{\circ} 23^{\prime} \mathrm{E}\right)$, Taihangshan Grand Canyon, 6.VIII.2010, Sheng-Tao Guo leg. Paratypes: 8ð, 37으, same data as holotype; 53ㅊ, 61오. Shanxi Province, Licheng County $\left(36^{\circ} 56^{\prime} \mathrm{N}, 113^{\circ} 40^{\prime} \mathrm{E}\right)$, Huangya Cave, 2. VIII. 2010, Zhi-Zhong Gao leg.; 8 , 34, Shanxi Province, Zuoquan County $\left(37^{\circ} 07^{\prime} \mathrm{N}, 113^{\circ} 35^{\prime} \mathrm{E}\right)$, Longquan Forest Park, 28.VII.2010, Yun Wang leg.; 7ð, 7q, Shanxi Province, Licheng County ( $\left.36^{\circ} 56^{\prime} \mathrm{N}, 113^{\circ} 40^{\prime} \mathrm{E}\right)$, Mount Guangzhi, 30.VII.2010, Sheng-Tao Guo leg. (MHBU).

Diagnosis. This new species is similar to Pholcus oculosus Zhang \& Zhang, 2000 in having similar palpal bulb and procursus, but can be distinguished by the shapes of appendix and procursus, the shorter ventral apophysis of trochanter, and the longer and slender epigynal apophysis. 

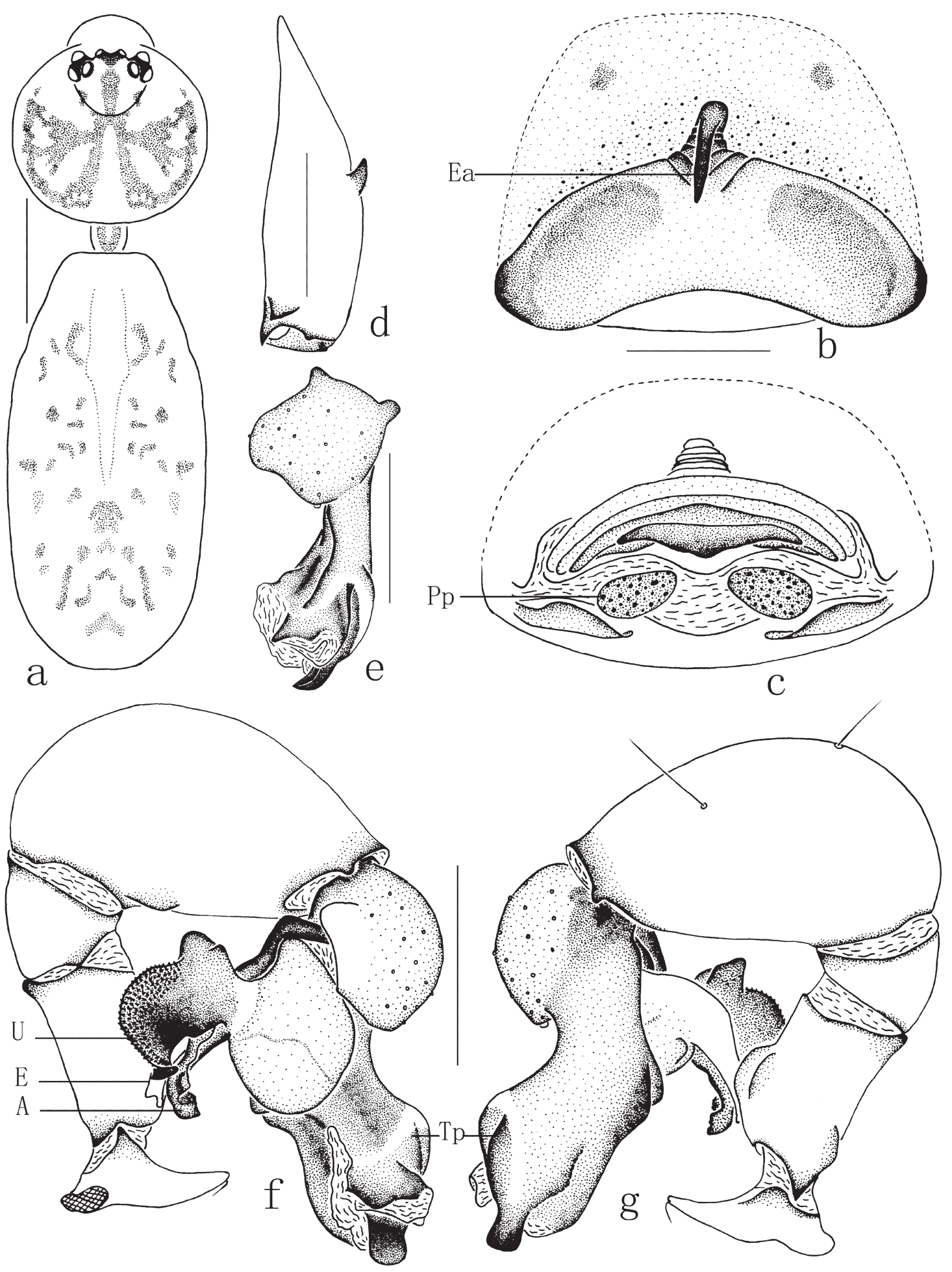

Fig. 2. Pholcus suboculosus sp. n. - a. Male body, dorsal view. - b. Epigynum, ventral view. - c. Epigynum, dorsal view. - d. Male left chelicera, frontal view. - e. Left procursus, dorsal view. - f. Left palp, prolateral view. - g. Left palp, retrolateral view. Scale lines: a, $1.0 \mathrm{~mm} ; \mathrm{b}-\mathrm{g}, 0.5 \mathrm{~mm}$. Abbreviations as in Fig. 1. 
Description. Male holotype. Total body length 5.32: cephalothorax 1.62 long, 1.74 wide; abdomen 3.70 long, 1.71 wide. Leg I: 32.69 (7.72 $+0.62+8.40+13.24+2.71)$, tibia II: 5.60 , tibia III: 3.92, tibia IV: 5.59; tibia I L/D: 61.45 . Prosoma shape as in Fig. 2a. Carapace short, broad, almost circular, ochre, with broad brown marks extending to ocular area; cephalic region raised, with a brown stripe centrally; ocular area dark yellow; clypeus 0.73 , ochre, without marks. AME-AME 0.05. Diameter AME 0.07, ALE 0.18 , PME 0.16, PLE 0.16. Chelicerae with a pair of black apophyses distally and a pair of unsclerotized thumb-shaped apophyses proximolaterally (Fig. 2d). Sternum ochre, with large yellow marks. Femora, patellae and tibiae ochre, with dark rings, metatarsi and tarsi brown. Abdomen cylindrical, pale ochre, dorsum with brown spots (Fig. 2a). Venter pale brown, without marks. Palpal trochanter ventral apophysis short, distally with a small and short spine; bulb with three projections: short appendix, short embolus and S-shaped uncus, uncus with small scales; procursus with complicated tip and a dark, narrow, curved apophysis distally (figs. $2 \mathrm{e}-\mathrm{g}$ ).

Variation. Other males $(N=77)$ : Tibia I 8.44 9.58, body length 4.60-5.57.

Female. Similar to male. Body length of paratypes 5.57-5.89. One female paratype (from Huangya Cave, Licheng County) was measured: total length 5.57, cephalothorax 1.75 long, 1.70 wide; abdomen 3.82 long, 1.85 wide. Tibia I: 8.23. AME-AME 0.04. Diameter AME 0.08, ALE 0.16, PME 0.13, PLE 0.13. Epigynum roughly triangular (Fig. 2b), with a whip-shaped apophysis anteriorly and a pair of semicircular dark marking medially; dorsal view as in Fig. 2c, with wavy sclerotized arch anteriorly, and a pair of egg-shaped pore plates posteriorly.

Etymology. The specific name is referring to its similarity to Pholcus oculosus Zhang \& Zhang, 2000.

Distribution. China (Shanxi).

\subsection{Pholcus oculosus Zhang \& Zhang, 2000 (Figs. 3a-g)}

Pholcus oculosus Zhang \& Zhang 2000: 151, f. 1A-F; Zhang \& Zhu 2009: 60, f. 30A-E.
Type material. Holotype: $\hat{\jmath}$, Hebei Province, Wu'an County, Liejiang Town, 19. V. 1999, Feng Zhang leg. Paratypes: $2 \hat{\jmath}$, same data as holotype (MHBU) (examined).

Other material examined. China: $2 \hat{\jmath}, 21 \stackrel{\text {, }}{ }$ Shanxi Province, Heshun County $\left(37^{\circ} 33^{\prime} \mathrm{N}\right.$, $113^{\circ} 55^{\prime}$ E), Yangqu Mount, 25.VII.2010, ShengTao Guo leg.; $5 \hat{\jmath}, 3$, , Shanxi Province, Heshun

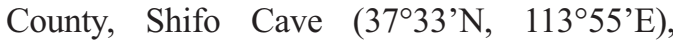
24.VII.2010, Zhi-Zhong Gao leg.; 1今̄, 26우, Shanxi Province, Zuoquan County, Longquan Town (3707'N, 11335'E), 29.VII.2010, Yun Wang leg. (MHBU).

Diagnosis. This species resembles Pholcus suboculosus sp. n. in having a similar palpal bulb and procursus, but can be distinguished by the shapes of appendix and the tip of procursus, the longer ventral apophysis of trochanter, and the broader epigynal apophysis.

Redescription. Total length of male specimen 4.93-5.35. One male specimen (from Shifo Cave, Heshun County) was measured, total body length 4.93: cephalothorax 1.50 long, 1.61 wide; abdomen 3.43 long, 1.58 wide. Leg I: 36.47 (9.66+ $0.65+9.72+14.30+2.14)$, tibia II: 6.66 , tibia III: 4.86, tibia IV: 6.69; tibia I L/D: 53.32. Prosoma shape as in Fig. 3a. Carapace short, broad and almost circular, ochre, with pair of brown central marks broadly connecting to ocular area; cephalic region raised; clypeus 0.71 , slightly ochre, with brown marks centrally. AME-AME 0.05. Diameter AME 0.09, ALE 0.16, PME 0.17, PLE 0.16. Chelicerae with a pair of black apophyses distally and a pair of unsclerotized thumb-shaped apophyses proximolaterally (Fig. 3d). Labium and endites yellowish brown. Sternum ochre, with a few irregular yellow marks. Femora, patellae and tibiae ochre, with dark rings, metatarsi and tarsi brown. Abdomen cylindrical, pale ochre, dorsum with numerous brown spots (Fig. 3a). Venter pale brown, without marks. Palpal trochanter with long ventral apophysis; bulb with three projections: short appendix, short embolus and Sshaped uncus, uncus with small scales; procursus with complicated tip and a dark, wide, curved apophysis distally (figs. $3 \mathrm{e}-\mathrm{g}$ ).

Female. Similar to male. Total length of bodies 5.84-6.05. One female specimen (from Shifo Cave, Heshun County) was examined, with total length 5.84: cephalothorax 1.62 long, 1.61 wide; 

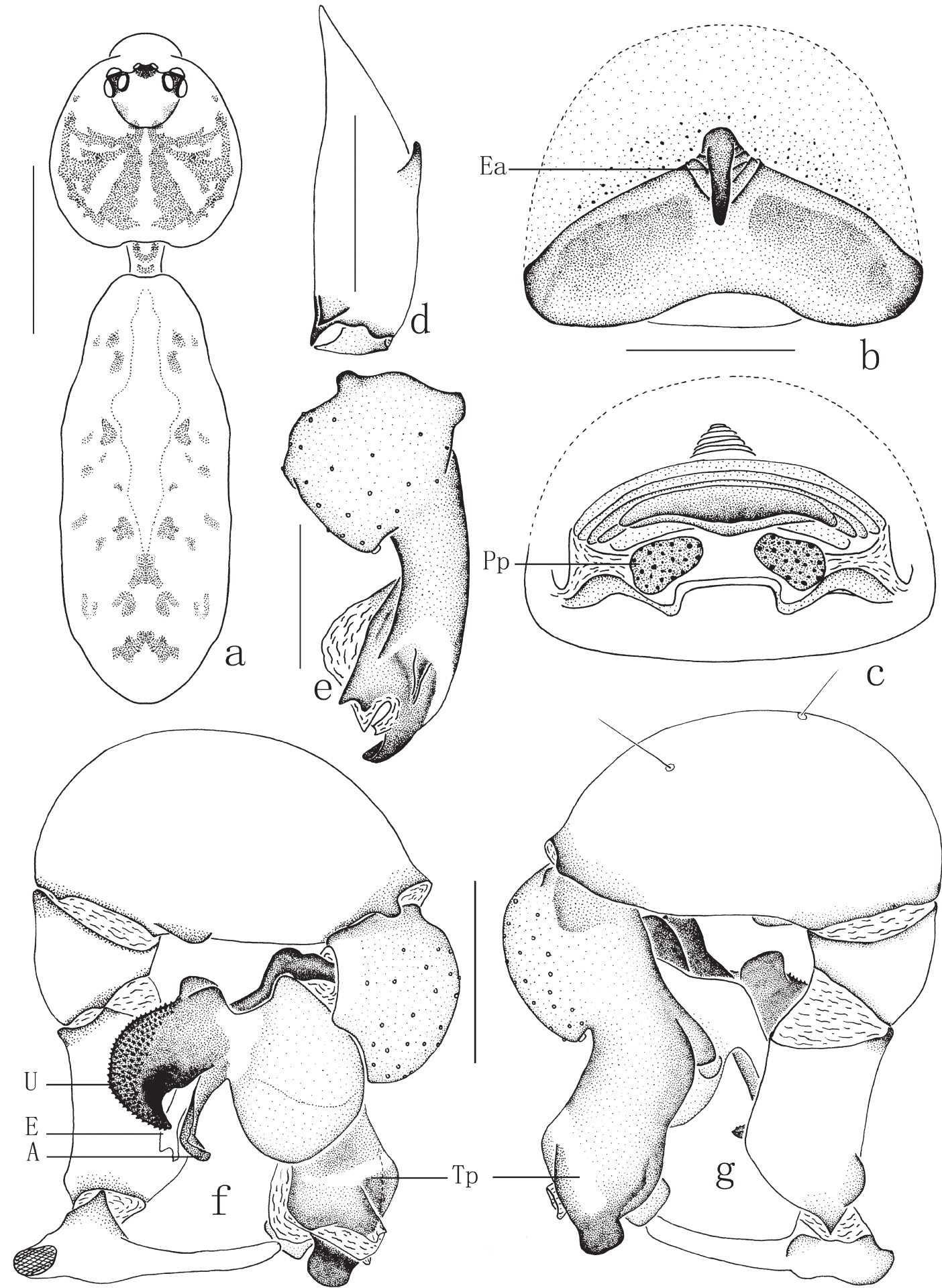

Fig. 3. Pholcus oculosus Zhang \& Zhang, 2000. - a. Male body, dorsal view. - b. Epigynum, ventral view. - c. Epigynum, dorsal view. - d. Male left chelicera, frontal view. - e. Left procursus, dorsal view. - f. Left palp, prolateral view. - g. Left palp, retrolateral view. Scale lines: a, $1.0 \mathrm{~mm}$; b-g, $0.5 \mathrm{~mm}$. Abbreviations as in Fig. 1. 
abdomen 4.22 long, 1.62 wide. Tibia I: 7.28. Distance AME-AME 0.05. Diameter AME 0.07, ALE 0.16, PME 0.15, PLE 0.15. Epigynum roughly triangular (Fig. 3b), with a thick whipshaped apophysis anteriorly and a pair of semicircular dark marking medially; dorsal view as in Fig. 3c, with wavy sclerotized arch anteriorly, and a pair of triangular pore plates posteriorly.

Distribution. China (Hebei, Shanxi).

Acknowledgements. We are grateful to Mr. Sheng-Tao Guo, Zhi-Zhong Gao and Yun Wang for collecting the valuable specimens. Many thanks are also due to two anonymous referees for valuable comments. Dr. Xinping Wang kindly helped reviewing the manuscript. This work was supported by the National Natural Science Foundation of China (No. 31071885, 31093430) and by the Doctoral Program Foundation of Institutions of Higher Education of China (No. 20091301120005) to Dr Feng Zhang.

\section{References}

Hu, J. L. 2001: Spiders in Qinghai-Tibet Plateau of China. - Henan Science and Technology Publishing House, Zhengzhou. 658 pp.

Huber, B. A. 1995: Copulatory mechanism in Holocnemus pluchei and Pholcus opilionoides, with notes on male cheliceral apophyses and stridulatory organs in Pholcidae (Araneae). - Acta Zoologica 76: 291-300.

Huber, B. A. 1998: Genital mechanics in some neotropical pholcid spiders (Araneae: Pholcidae), with implications for systematics. - Journal of Zoology 244: 587599.

Huber, B. A. 2000: New World pholcid spiders (Araneae: Pholcidae): a revision at generic level. — Bulletin of the American Museum of natural History 254: 1-348.

Huber, B. A. 2001: The pholcids of Australia (Araneae; Pholcidae): Taxonomy, biogeography, and relationships. - Bulletin of the American Museum of natural History 260: 1-144.

Li, S. Q. \& Wang, X. P. 2011: Endemic spiders in China. - [www document]. URL http://www.Chinese Species. com. (Site visited on 22 February, 2011)

Platnick, N. I. 2011: The world spider catalog, version 11.5. - American Museum of Natural History. [www document]. URL http://research.amnh.org/entomology/ spiders /catalog/index.html. (Site visited on 22 February, 2011)

Simon, E. 1893: Histoire naturelle das araignées. $-2^{\text {nd }}$ edition, Roret, Paris 1: 257-488.

Song, D. X., Zhu, M. S. \& Chen, J. 1999: The Spiders of China. - Hebei Science Technology Publishing House, Shijiazhuang 640 pp.

Tong, Y. F. \& Ji, L. Z. 2010: Three new species of the spider genus Pholcus (Araneae: Pholcidae) from Liaodong Mountain, China. — Entomologica Fennica 21: 97103

Tong, Y. F. \& Li, S. Q. 2010: Eight new spider species of the genus Pholcus (Araneae, Pholcidae) from China. - Zootaxa 2355: 35-55.

Walckenaer, C. A. 1805: Tableau des aranéides ou caractères essentiels des tribus, genres, familles et races que renfermele genre Aranea de Linné, avec la désignation des espèces comprises dans chacune de ces divisions. - Paris 88pp.

Zhang, F. \& Zhang, J. X. 2000: Three new species and a new discovery of female of genus Pholcus (Araneae: Pholcidae) from Taihang Mts., China. - Journal of Hebei University 20: 151-156.

Zhang, F., Zhu, M. S. \& Song, D. X. 2005: A new species of the genus Pholcus (Araneae, Pholcidae) from Taihang Mountains area, China. - Acta zootaxonomica Sinica 30: 65-66.

Zhang, F. \& Zhu, M. S. 2009: A review of the Pholcus (Araneae: Pholcidae) from China. — Zootaxa 2037: $1-114$.

Zhu, C. D., Mao, J. Y. \& Yu, Z. X. 1983: Two new species of spiders of the genus Pholcus from China (Araneae: Pholcidae). - Journal Bethune University of Medical Sciences 9 (suppl.): 135-137.

Zhu, M. S., Tu, H. S. \& Shi, J. G. 1986: Spiders of the genus Pholcus (Araneae: Pholcidae) from Shanxi and Shaanxi Provinces, China, with description of a new species. - Journal of Hebei Normal University 2: 118-124. 